\title{
Chemical Characterization of Chinese Perilla Seed Oil
}

\author{
Beibei Zhao, Shijian Fu, Hua Li* , and Zhicheng Chen \\ College of Food Science and Engineering, Henan University of Technology, Lianhua Road, Zhengzhou, 450001, CHINA
}

\begin{abstract}
Physicochemical properties and chemical composition of Chinese perilla seed oil has been characterized in this study. The result showed that both the cold press oil and the solvent extracted oil possessed low acid value and peroxide value. The fatty acid composition result showed that the oil has high content of linolenic acid (C18:3) up to $66.4 \mathrm{~g} / 100 \mathrm{~g}$, followed by linoleic acid (C18:2) of $15.3 \mathrm{~g} / 100 \mathrm{~g}$. The total triacylglycerol (TAG) profiles results showed that the oil contained 20 TAGs including 17 regioisomers, including LnLnLn (35.8 g/100 g), LLnLn (20.2 g/100 g), LLLn (17.7 g/100 g) and PLnLn (14.9 g/100 g) (Ln, linolenic acid; L, linoleic acid; $P$, palmitic acid). With content of only $0.57 \mathrm{~g} / 100 \mathrm{~g}$ oil, the unsaponifiable matters were mainly composed of phytosterols, squalene, tocopherol, alcohols and hydrocarbons. The total phytosterols content was $0.39 \mathrm{~g} / 100 \mathrm{~g}$ oil, in which $\beta$-sitosterol has high content of $0.31 \mathrm{~g} / 100 \mathrm{~g}$ oil.
\end{abstract}

Key words: fatty acid composition, perilla seed oil, triacylglycerol, unsaponifiable matter

\section{Introduction}

Perilla (Perilla frutescens L.) is an annual aromatic plant that belongs to the Labiatae family. Perilla is now widely distributed in China, Southeast Asia, Europe and North America $^{1)}$. The perilla seed oil has high $\alpha$-linolenic acid (C18:3, ALA) level of 52.58-61.98 g/100 g oil ${ }^{2}$. It also contains natural antioxidants, including tocopherols, squalene, flavonoids, phytosterols, and so on ${ }^{3}$. With good nutritional properties, perilla seed oil is an important edible oil in many countries ${ }^{4)}$. It is widely used in cosmetics, skincare products and medicinal preparations on purpose of anticancer, anti-inflammatory, mental health care, cardiocerebrovascular diseases treatment, and so on ${ }^{5-7)}$. Perilla seed oil is now used to make health care drugs, such as capsules and oil drops, in China.

Several extraction methods of the perilla oil were investigated, such as solvent extraction, aqueous enzymatic extraction, mechanical pressing and supercritical extraction ${ }^{8)}$. Supercritical extraction and aqueous enzymatic extraction methods are costly, and solvent extraction is effective and commonly used. Although the yield of the mechanical pressing was relatively lower than other methods, the loss of active ingredients such as linolenic acid and phytosterols was avoided in the cold pressing process ${ }^{9)}$. The triacylglycerols (TAG) composition of the oil have been determined by non-aqueous reversed-phase HPLC method (NARP), but only five TAGs were detected, including LnLnLn, LnLnL,
LnLL, LnLnO and LnLnP(Ln, linolenic acid; L, linoleic acid; $\mathrm{P}$, palmitic acid; O, oleic acid ${ }^{10}$.

However, the overall TAG profiles and the positional isomers of the perilla seed oil was still unknown. In this study, chemical composition of Chinese perilla seed oil was analyzed, especially the overall TAG and unsaponifiable matters compositions, in the objective of better utilization and further research of the perilla seed oil.

\section{Materials and Methods \\ 2.1 Materials}

Perilla seed samples were collected from a perilla farm in Huaihua (Hunan Province, Northeast of China). After removing the impurity, perilla seeds were milled in a FW100 crusher (Taisite, Tianjin, China) and was sieved through a 2 $\mathrm{mm}$ mesh screen. The raw material (total carbohydrate $9.20 \%$, protein $21.29 \%$, oil $45.56 \%$, moisture $5.68 \%$, ash $4.14 \%$ and crude fiber $15.69 \%$ ) was stored at $4^{\circ} \mathrm{C}$ in a sealed pouch. $\alpha$-Colestanol, eicosanol, and BSTFA + TMCS (99:1) of analytical grade were from Supelco. Fatty acid esters and tocopherol $(\alpha-, \beta$-, $\gamma$ - and $\delta$-isomers) standards used for chromatography analyses were from Sigma-Aldrich. Other solvents were of analytical grade and purchased from Kermel(Tianjin, China).

\footnotetext{
*Correspondence to: Hua Li, College of Food Science and Engineering, Henan University of Technology, Lianhua Road, Zhengzhou, 450001, CHINA

E-mail: lixian78101@163.com

Accepted July 9, 2021 (received for review March 1, 2021)

Journal of Oleo Science ISSN 1345-8957 print / ISSN 1347-3352 online

http://www.jstage.jst.go.jp/browse/jos/ http://mc.manusriptcentral.com/jjocs

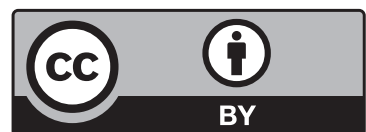




\subsection{Perilla seed oil extraction}

Two methods were selected for oil extraction: solvent extraction and cold pressing. The perilla seed powder of $100 \mathrm{~g}$ was extracted by $600 \mathrm{~mL} n$-hexane at $40^{\circ} \mathrm{C}$. The extraction was carried out for $8 \mathrm{~h}$. The solvent was collected, evaporated and centrifuged, after which the perilla seed oil was obtained. Cold pressing was carried out using a screw oil press (CA-59-G model, TBG, Germany) without heat treatment. The obtained oil was stand for $30 \mathrm{~min}$, and then centrifuged at $3500 \mathrm{r} / \mathrm{min}$ for $10 \mathrm{~min}$ to separate oil from sediments ${ }^{11)}$. Both oil samples were stored at $-20^{\circ} \mathrm{C}$ in amber bottles to avoid oxidization.

\subsection{Analysis of the perilla seed oil}

\subsubsection{Physicochemical parameters}

Determination of acid value $(\mathrm{AV})$, peroxide value $(\mathrm{PV})$, saponification value, and unsaponifiable matter content of the oil was carried out according to AOCS methods ${ }^{12)}$.

The tocopherol $(\alpha-, \beta-, \gamma$ - and $\delta$-isomers $)$ level of the oil were determined as described by ${ }^{13)}$ using an Agilent 1200 HPLC system (Agilent, USA) equipped with Supelcosil LC-Si column $(250 \times 4.6 \mathrm{~mm}, 5 \mu \mathrm{m})$ (Supelco, USA) and fluorescence detector. The emission and excitation wavelength were set at 330 and $290 \mathrm{~nm}$, respectively. The column temperature was held at $20^{\circ} \mathrm{C}$. The oil samples were dissolved in hexane at $100 \mathrm{mg} / \mathrm{mL}$. A $5 \mu \mathrm{L}$ volume of the loaded sample on the column was eluted with $n$-hexane/isopropyl ether $(93 / 7, \mathrm{v} / \mathrm{v})$ isocratically at $1.5 \mathrm{~mL} / \mathrm{min}$. The absolute contents of tocopherols were determined by comparison with the calibrated standard curves.

\subsubsection{Fatty acid composition}

Derivatisation reaction of the oil was carried out by using the literature method ${ }^{14)}$. Analysis of the obtained fatty acid methyl esters was carried out on Agilent 7890B gas chromatograph system equipped with BPX70 capillary column $(30 \mathrm{~m} \times 320 \mu \mathrm{m} \times 0.5 \mu \mathrm{m})$ (Agilent, USA) and flame ionization detector (FID). The column, injector, and detector temperatures were set at 210,230 , and $300^{\circ} \mathrm{C}$, respectively. The flow rate of carrier gas $\mathrm{N}_{2}$ with split ratio of 1:50 was set at $50 \mathrm{~mL} / \mathrm{min}$. The fatty acids were identified with reference to the retention times of standard fatty acid methyl ester performed at the same conditions.

2.3.3 TAG profile analysis

Overall TAG profile analysis was carried out using offline 2D HPLC system coupled with atmosphere pressure chemical ionisation (APCI) MS according to the literature ${ }^{15)}$. The oil sample was first separated by non-aqueous reversed-phase (NARP) using Agilent 1200 HPLC system equipped with an Agilent ZORBAX SB-C18 column $(250 \times$ $4.6 \mathrm{~mm}, 5 \mu \mathrm{m})$. Each fraction of the NARP eluent was collected following ten injections. Same fractions were combined and condensed by nitrogen dryer. Fractions collected in NARP dimension were solubilized in hexane, and then injected into the silver ion HPLC (Ag-HPLC) system, using
Agilent 1200 HPLC system equipped with Agilent ChromSpher 5 Lipids column $(250 \times 4.6 \mathrm{~mm}, 5 \mu \mathrm{m})$. LC-MS detection was achieved through Agilent 6300 Mass Spectrometer Detector ion trap (Agilent, USA) equipped with APCI.

2.3.4 Unsaponifiable matters of the oil

Saponification reaction was performed at present of internal standards ( $\alpha$-colestanol and eicosanol) according to the literature ${ }^{15)}$. The obtained unsaponifiable matters was then boiled with BSTFA + TMCS (99:1) for derivatisation reaction.

Derivated unsaponifiable matters were analyzed by Agilent GC-7890B GC-MS with an HP-5MS column (30 m × $250 \mu \mathrm{m} \times 0.25 \mu \mathrm{m}$, Agilent, USA); carrier gas: helium; flow rate: $1 \mathrm{~mL} / \mathrm{min}$; injection temperature: $280^{\circ} \mathrm{C}$; detection temperature: $280^{\circ} \mathrm{C}$. The temperature was firstly kept at $50^{\circ} \mathrm{C}$ for $1 \mathrm{~min}$, increased from $50^{\circ} \mathrm{C}$ to $150^{\circ} \mathrm{C}$ at $8^{\circ} \mathrm{C} / \mathrm{min}$ and kept at $150^{\circ} \mathrm{C}$ for $1 \mathrm{~min}$, then increased from $150^{\circ} \mathrm{C}$ to $300^{\circ} \mathrm{C}$ at $5^{\circ} \mathrm{C} / \mathrm{min}$, and kept at $300^{\circ} \mathrm{C}$ for $10 \mathrm{~min}$ at last. MS parameters were as follows: electronic ionization voltage, $70 \mathrm{eV}$; ion source temperature, $250^{\circ} \mathrm{C}$; scan range, $\mathrm{m} / \mathrm{z} 50$ $550^{16)}$. Unsaponifiable matters identification was performed by comparison of the retention times and mass spectra of eluting compounds to those of the Wiley library(WILEY 275, NIST 98; Wiley, West Sussex, UK).

\subsection{Statistical analysis}

All experiments were repeated in triplication, and results were expressed as mean \pm standard deviation.

\section{Results and Discussion}

\subsection{Physicochemical parameters of perilla seed oil}

Table 1 shows the physicochemical properties of the perilla seed oil. The oil yield of the solvent extracted method was up to $39.61 \mathrm{~g} / 100 \mathrm{~g}$, while that of the cold press method was only $34.40 \mathrm{~g} / 100 \mathrm{~g}$. Both of them were higher than the aqueous enzymatic extracted method $(31.28 \mathrm{~g} / 100 \mathrm{~g})^{17)}$. Recently, the oil yield has been reported to be $78.81 \mathrm{~g} / 100 \mathrm{~g}$ by superheated steam treatment method $^{14)}$ and $78.81 \mathrm{~g} / 100 \mathrm{~g}$ by freeze-thaw pretreatment method $^{18)}$. Both oil presented pleasant golden yellow color. Low acid value $(0.57$ and $0.62 \mathrm{mg} \mathrm{KOH} / \mathrm{g}$ oil $)$ and peroxide value $\left(1.60\right.$ and $1.78 \mathrm{meq} \mathrm{O}_{2} / \mathrm{kg}$ oil) indicated good quality of the oil. But the aqueous enzymatic extracted oil possessed relatively higher acid value (3.06 mg KOH/g oil) and peroxide value $\left(3.20 \text { meq } \mathrm{O}_{2} / \mathrm{kg} \text { oil }\right)^{17}$. High iodine value indicated high unsaturated fatty acids content of the two oils. Total content of tocopherols in the solvent extracted oil was up to $743.3 \mathrm{mg} / \mathrm{kg}$ oil, higher than the peanut oil (345.0 mg/kg oil), peanut oil (455.0 mg/kg oil), and most grape seed oil $(397.8-755.8 \mathrm{mg} / \mathrm{kg})^{19-21)}$. It has been reported that the tocopherol content of polyunsaturated fatty acid (PUFA) rich oils was higher than that of the oleic acid- 


\section{Perilla Seed Oil}

Table 1 Physicochemical characteristics of Chinese perilla seed oil.

\begin{tabular}{|c|c|c|c|c|}
\hline Determination & $\begin{array}{l}\text { Cold Press PS- } \\
\text { CHI oil }\end{array}$ & $\begin{array}{l}\text { Solvent extracted } \\
\text { PS-CHI oil }\end{array}$ & $\begin{array}{c}\text { Aqueous enzymatic } \\
\text { extracted PS-CHI oil } \\
(17)\end{array}$ & $\begin{array}{c}\text { Ultrasound-assisted } \\
\text { hexane extracted PS } \\
\text { oil (9) }\end{array}$ \\
\hline Oil yield (g/100 g) & $34.40 \pm 0.75$ & $39.61 \pm 0.71$ & 31.28 & 36.30 \\
\hline Color & $\begin{array}{l}\text { Golden yellow, } \\
\text { transparent }\end{array}$ & $\begin{array}{l}\text { Golden yellow, } \\
\text { transparent }\end{array}$ & Yellow & Yellow \\
\hline Acid value (mg KOH/g oil) & $0.57 \pm 0.02$ & $0.62 \pm 0.03$ & $3.06 \pm 0.03$ & $0.77 \pm 0.05$ \\
\hline Peroxide value (meq $\mathrm{O}_{2} / \mathrm{kg}$ oil) & $1.60 \pm 0.03$ & $1.78 \pm 0.06$ & $3.20 \pm 0.03$ & $1.71 \pm 0.15$ \\
\hline Iodine value ( $\mathrm{g} \mathrm{I}_{2} / 100 \mathrm{~g}$ oil $)$ & $197.6 \pm 1.7$ & $194.4 \pm 1.6$ & $210.6 \pm 0.4$ & $176.7 \pm 0.4$ \\
\hline Saponification value (mg KOH/g oil) & $189.6 \pm 2.2$ & $185.8 \pm 1.7$ & $196.5 \pm 0.5$ & $206.7 \pm 0.4$ \\
\hline Unsaponifiable matter (g/100 g oil) & $0.57 \pm 0.11$ & $0.58 \pm 0.14$ & N.G. & $0.60 \pm 0.12$ \\
\hline Tocopherol (mg/kg of oil) & & & $450.9 \pm 1.4$ & \\
\hline$\alpha$ & $27.8 \pm 0.6$ & $30.5 \pm 0.6$ & N.G. & $33.5 \pm 0.0$ \\
\hline$\beta$ & N.D. & N.D. & N.G. & N.D. \\
\hline$\gamma$ & $685.4 \pm 5.4$ & $712.8 \pm 7.3$ & N.G. & $453.9 \pm 0.0$ \\
\hline$\delta$ & N.D. & N.D. & N.G. & $10.9 \pm 0.0$ \\
\hline
\end{tabular}

Results are presented as mean value \pm standard deviation $(n=3)$.

PS-CHI, perilla seed samples harvested from Sichuan Province of China; N.D., not detected; N.G., not given.

Table 2 Fatty acid composition of the cold press Chinese perilla seed oil (g/100 g).

\begin{tabular}{lccc}
\hline \multicolumn{1}{c}{ Fatty acid } & Cold Press PS-CHI oil & $\begin{array}{c}\text { Aqueous enzymatic } \\
\text { extracted PS-CHI oil (17) }\end{array}$ & $\begin{array}{c}\text { Ultrasound-assisted hexane } \\
\text { extracted PS-CHI oil (9) }\end{array}$ \\
\hline Palmitic acid (C16:0) & $5.6 \pm 0.0$ & $4.4 \pm 0.1$ & $4.1 \pm 0.2$ \\
Stearic acid (C18:0) & $1.5 \pm 0.0$ & $1.9 \pm 0.0$ & $1.9 \pm 0.0$ \\
Oleic acid (C18:1) & $11.3 \pm 0.0$ & $20.4 \pm 0.2$ & $16.7 \pm 0.1$ \\
Linoleic acid (C18:2) & $15.3 \pm 0.0$ & $9.1 \pm 0.1$ & $14.3 \pm 0.1$ \\
Linolenic acid (C18:3) & $66.4 \pm 0.0$ & $64.1 \pm 0.2$ & $61.9 \pm 0.1$ \\
SFA & 7.0 & 6.3 & 7.0 \\
MUFA & 11.3 & 20.4 & 16.8 \\
PUFA & 81.7 & 73.2 & 76.3 \\
USFA & 93.0 & 93.6 & 93.0 \\
PUFA/SFA & 11.6 & 11.6 & 10.9 \\
\hline
\end{tabular}

Results are presented as mean value \pm standard deviation $(n=3)$.

PS-CHI, perilla seed samples harvested from Sichuan Province of China; SFA, saturated fatty acids; MUFA, monounsaturated fatty acids; PUFA, polyunsaturated fatty acids; USFA, unsaturated fatty acids.

rich oils ${ }^{22)}$. With good antioxidant, tocopherol in the perilla oil could reduce free radical, therefore protecting the unsaturated fatty acids of the oil ${ }^{1)}$. However, the unsaponifiable matter of this oil was only $0.57 \mathrm{~g} / 100 \mathrm{~g}$, relatively lower than oliver oil(1.23 g/100 g), peanut oil(0.94 g/100 $\mathrm{g})$ and sunflower oil $(0.81 \mathrm{~g} / 100 \mathrm{~g})^{23)}$.

\subsection{Fatty acid composition}

Fatty acid composition of the cold press perilla seed oil was shown in Table 2. The majority fatty acid of the perilla seed oil was $\alpha$-linolenic acid (C18:3, ALA) at concentration of $66.4 \mathrm{~g} / 100 \mathrm{~g}$, which has high nutrition and medicinal value. This was comparable to that of the aqueous enzymatic extracted oil (64.1 g/100 g) and ultrasound-assisted hexane extracted oil $(61.9 \mathrm{~g} / 100 \mathrm{~g})$. It has been reported that after a series of metabolic activities in the body, ALA could finally produce eicosapentaenoic acid (EPA) and docosahexaenoic acid (DHA), which are especially beneficial to human health ${ }^{24)}$. The common commercial oils contain relatively lower content of ALA, such as soybean oil(5.0$11.0 \mathrm{~g} / 100 \mathrm{~g})$, rapeseed oil (5.0-13.0 g/100 g) and peanut oil $(<0.3 \mathrm{~g} / 100 \mathrm{~g})^{25)}$. The ALA content of the perilla seed oil 
was higher than that other ALA rich oils, such as linseed oil $(52.1 \mathrm{~g} / 100 \mathrm{~g})$, sacha inchi oil (50.7 g/100 g), and chia oil $(63.5 \mathrm{~g} / 100 \mathrm{~g})^{26,27)}$. The second one was linoleic acid (C18:2) with concentration of $15.3 \mathrm{~g} / 100 \mathrm{~g}$, while the third one was oleic acid (C18:1) at $11.3 \mathrm{~g} / 100 \mathrm{~g}$. The unsaturated fatty acids content was $93.0 \mathrm{~g} / 100 \mathrm{~g}$, among which polyunsaturated fatty acids amounted up to $81.7 \mathrm{~g} / 100 \mathrm{~g}$. The polyunsaturated/saturated fatty acids (PUFA/SFA) ratio reached up to $11.6 \mathrm{~g} / 100 \mathrm{~g}$. High PUFA/SFA ratio has been reported to be relative with reduction of cholesterol, therefore decreasing cardiovascular and atherosclerosis disease $^{28)}$.

\subsection{TAG composition}

The oil sample was separated into six TAGs fractions in NARP dimension, but baseline separation was not achieved in peak 3, 4 and 5(Fig. 1). Since the separation of TAGs in NARP was dependent on the equivalent carbon number (ECN), overall separation of TAGs with the same ECN could not be resolved by NARP. Especially positional isomers were always co-eluted in NARP-mode ${ }^{29)}$. For instance, PLnLn and LLLn with same ECN value of 40 are co-eluted in fraction 3, LLnP and OLnL with same ECN value of 42 are co-eluted in fraction 4, while PLL, POLn, LLO and OOLn with same ECN value of 44 are co-eluted in fraction 5. The separation of TAG in Ag-HPLC depends on the interaction of fatty acid double bonds and silver ions. Resolution of TAGs with the same ECN could be achieved by Ag-HPLC. Therefore, it is necessary to combine the NARP with the Ag-HPLC separation for overall TAGs profiles analysis.

Figure 2 shows the Ag-HPLC-MS chromatogram of fraction 1. As LnLnLn has no positional isomers, there is only

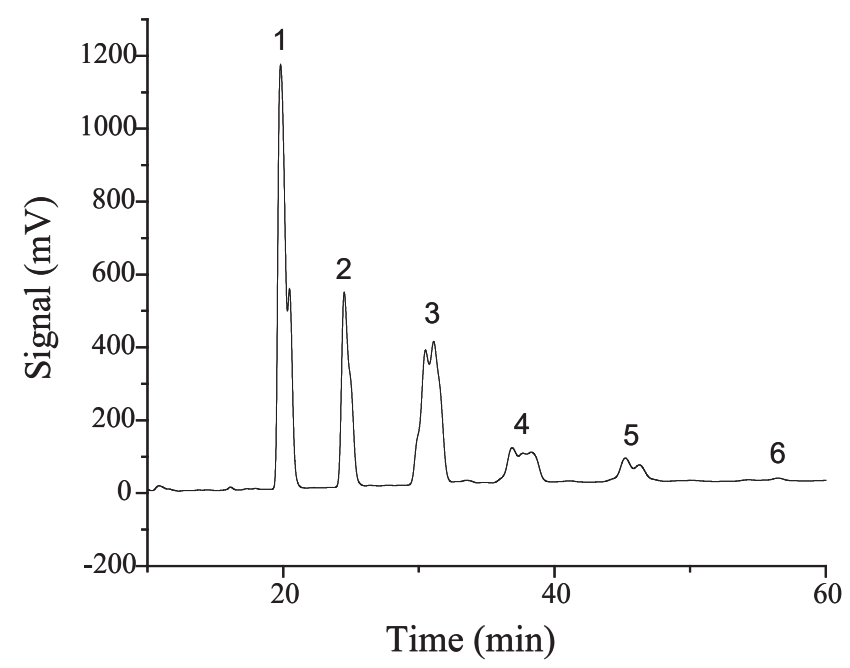

Fig. 1 NARP chromatogram of cold press Chinese perilla seed oil.

1. LnLnLn; 2. LLnLn; 3. PLnLn, LLLn; 4. LnPL, LLnO; 5. PLL, PLnO, LLO, OOLn; 6. SOLn. one peak in Ag-HPLC mode.

As shown in Fig. 3, fraction 2 is separated into two regioisomers in Ag-HPLC mode: $s n$-LLnLn and $s n$-LnLLn. With both linolenic acids located in $s n-1 / 3$ position, $s n$ LnLLn is more retained than $s n$-LLnLn.

Fraction 3 is separated into $s n$-PLnLn, sn-LnPLn, $s n$-LLnL and sn-LLLn in Ag-HPLC (Fig. 4). With a higher unsaturation degree, the LLnL group are more retained than the PLnLn group. As shown in Table 4, LLLn has 7 double bonds, while PLnLn has 6 double bonds. sn-LnPLn is more retained than $s n$-PLnLn due to the linolenic acids position. Similarly, $s n$-LLLn is more retained than $s n$-LLnL.

As shown in Fig. 5, fraction 4 is separated into 5 species: $s n$-LnLP, $s n$-LnPL, sn-LLnO, sn-LnLO and $s n$-LOLn. LnLO group are more retained because LnLO has 6 double bonds, more than $\operatorname{LnLP}(5)$. For the LnLP group, the relative abundance of $[\mathrm{LLn}]^{+}$(597.3) in the first peak is relatively higher the other peak, as well as that of $[\mathrm{PLn}]^{+}$

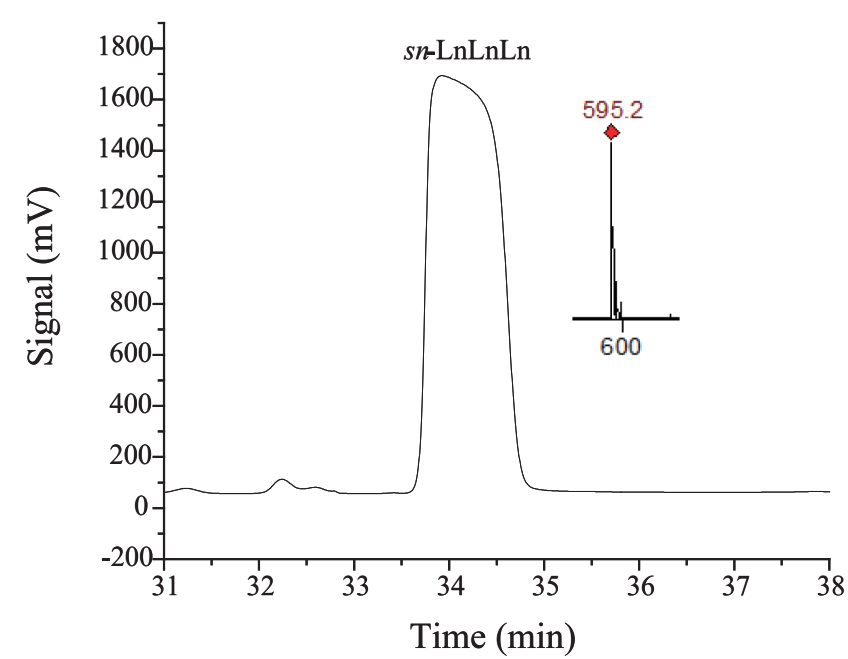

Fig. 2 Ag-HPLC-MS chromatogram of fraction 1.

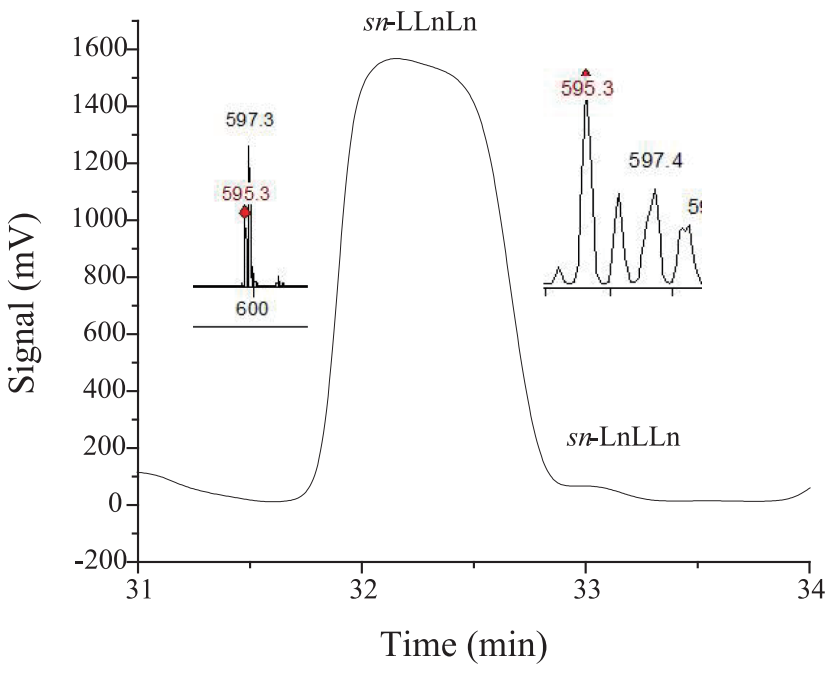

Fig. 3 Ag-HPLC-MS chromatogram of fraction 2. 
(573.3) in the second peak. $s n$-LnPL is more retained due to location of linoleic acid and oleic acid in $s n-1 / 3$ position. Therefore, the first peak is presumed to be $s n$-LnLP, and the second one is $s n$-LnPL. For the OLnL group, the relative abundance of $[\mathrm{LO}]^{+}(601.4)$ in the first peak is the lowest of the three peaks, as well as $[\mathrm{LnO}]^{+}(599.4)$ in the second peak and [LLn] ${ }^{+}$(597.6) in the third peak. Also, the retaining sequence is $s n$-LLnO, $s n$-LnLO and $s n$-LOLn. Therefore, the first peak is presumed to be $s n$-LLnO, the second one is $s n$-LnLO, and the third one is $s n$-LOLn.

As shown in Fig. 6, fraction 5 is separated into 7 species in Ag-HPLC. Having more double bonds (5), LLO and LnOO groups are more retained than LPL and POLn groups (4). With higher relative abundance of $[\mathrm{PL}]^{+}$ (575.3), the first peak is presumed to be $s n$-LPL. In the PLnO group, with lower relative abundance of $[\mathrm{PLn}]^{+}$ (573.4) and stronger retaining, the third peak is presumed to be $s n$-POLn. With lower relative abundance of $[\mathrm{PO}]^{+}$

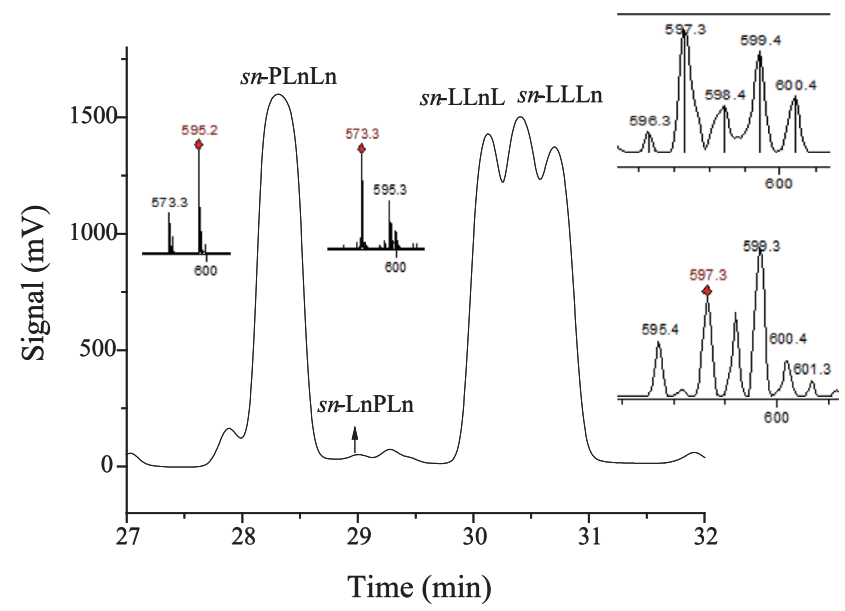

Fig. 4 Ag-HPLC-MS chromatogram of fraction 3.

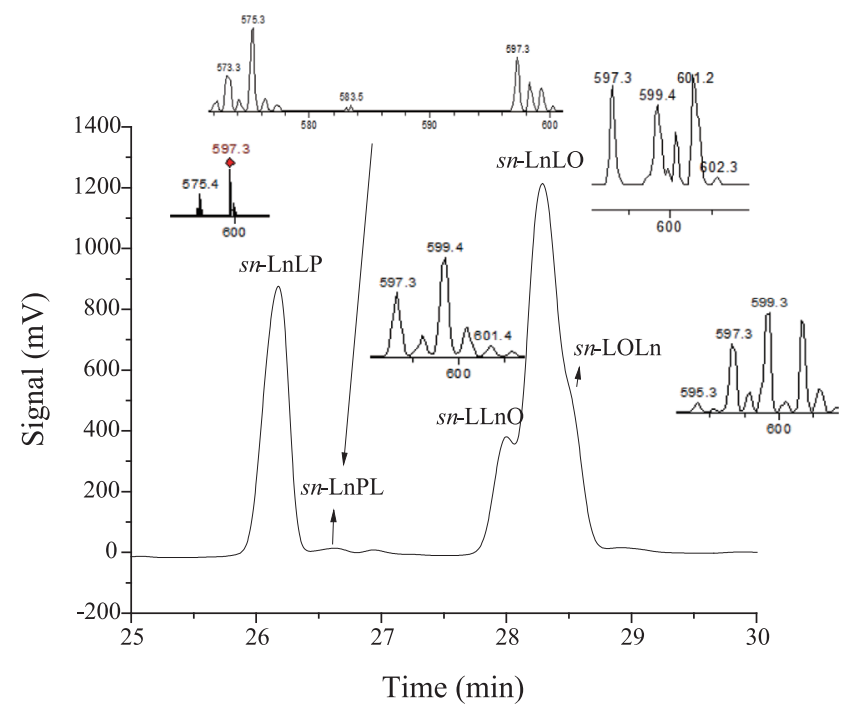

Fig. 5 Ag-HPLC-MS chromatogram of fraction 4.
(577.4), the second peak is $s n$-PLnO. For the LLO group, the relative abundance of [LL] ${ }^{+}$(599.4) in $s n$-LLO is higher than $s n$-LOL, and $s n$-LOL is more retained than $s n$-LLO. So the fourth peak is $s n$-LLO, and the fifth one is $s n$-LOL. In the sixth peak, the relative abundance of $[\mathrm{OLn}]^{+}$ (599.4) is higher than that of $[\mathrm{OO}]^{+}(603.5)$, so this one is sn-OLnO.

As shown in Fig. 7, fraction 6 is separated into 2 species: $s n$-OLnS (S, stearic acid) and sn-OSLn. The relative abundance of $[\mathrm{OS}]^{+}(605.4)$ in the first peak and $[\mathrm{OLn}]^{+}$ (599.4) in the second peak are relatively lower. Also, the retaining of $s n$-OSLn is stronger than $s n$-OLnS. So the first and second peak is $s n$-OLnS and sn-OSLn, respectively.

The TAG profiles of Chinese perilla seed oil analysis results were listed in Table 3. With content of $35.8 \mathrm{~g} / 100 \mathrm{~g}$, LnLnLn is the dominant TAG of this oil. Principal TAGs include LLnLn (20.2 g/100 g), LLLn (17.7 g/100 g) and PLnLn(14.9 g/100 g). Other TAGs are minor TAGs, such as

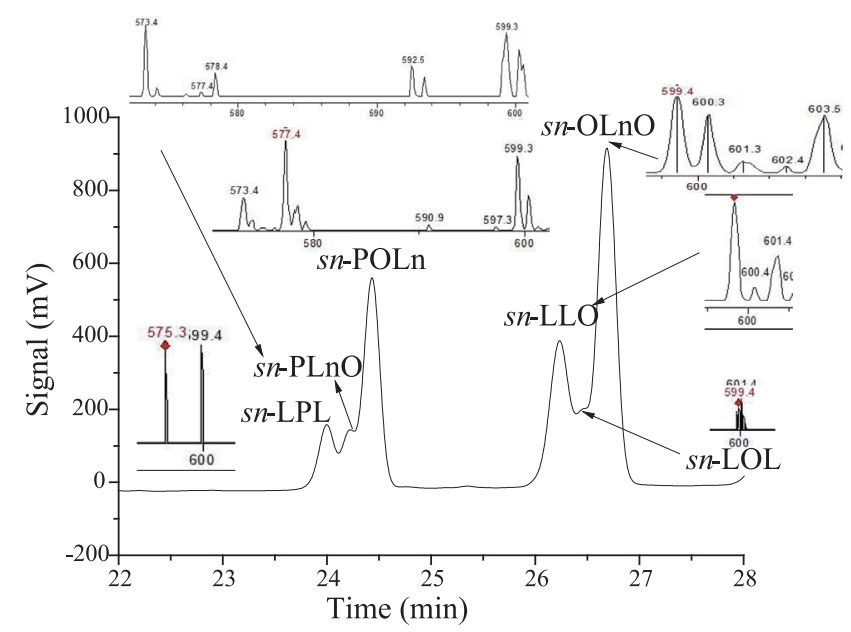

Fig. 6 Ag-HPLC-MS chromatogram of fraction 5.

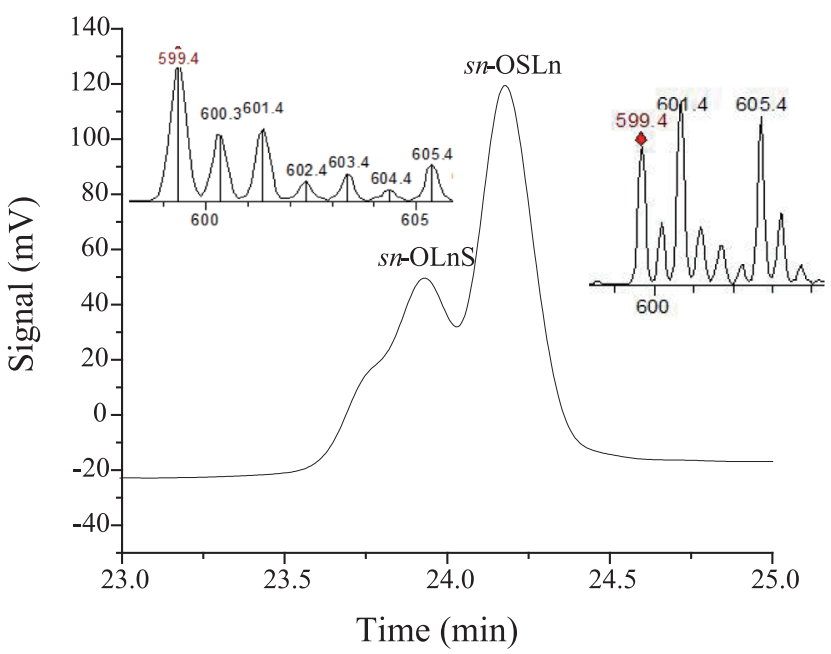

Fig. 7 Ag-HPLC-MS chromatogram of fraction 6. 
Table 3 Molecular mass, partition number, fragmentation ions obtained for TAGs identified in the cold press Chinese perilla seed oil by RPLC-HPLC-APCI-MS.

\begin{tabular}{ccccccccccc}
\hline Fraction & TAG & $\begin{array}{c}\text { Relative } \\
\text { abundance } \\
(\mathrm{g} / 100 \mathrm{~g})\end{array}$ & $\mathrm{Mr}$ & $\mathrm{DB}$ & $\mathrm{CN}$ & $\mathrm{ECN}$ & {$\left[\mathrm{M}+\mathrm{NH}_{4}\right]^{+}$} & {$[\mathrm{DG}]^{+}$} & {$[\mathrm{DG}]^{+}$} & {$[\mathrm{DG}]^{+}$} \\
\hline 1 & LnLnLn & $35.8 \pm 0.1$ & 872.7 & 9 & 54 & 36 & 890.7 & LnLn 595.5 & & \\
2 & LLnLn & $20.2 \pm 0.0$ & 874.7 & 8 & 54 & 38 & 892.7 & LLn 597.4 & LnLn 595.3 & \\
3 & PLnLn & $14.9 \pm 0.0$ & 850.6 & 6 & 52 & 40 & 868.6 & PLn 573.3 & LnLn 595.3 & \\
& LLLn & $17.7 \pm 0.0$ & 876.7 & 7 & 54 & 40 & 894.7 & LLn 597.3 & LL 599.3 & \\
4 & LnPL & $2.5 \pm 0.0$ & 852.7 & 5 & 52 & 42 & 870.7 & PLn 573.3 & PL 575.4 & LLn 597.3 \\
& LLnO & $4.2 \pm 0.0$ & 878.7 & 6 & 54 & 42 & 896.7 & LLn 597.3 & OLn 599.4 & LO 601.4 \\
5 & PLL & $0.8 \pm 0.0$ & 854.7 & 4 & 52 & 44 & 872.7 & LL 599.4 & PL 575.3 & \\
& PLnO & $1.6 \pm 0.0$ & 854.7 & 4 & 52 & 44 & 872.8 & PO 577.4 & PLn 573.3 & OLn 599.3 \\
& LLO & $1.1 \pm 0.0$ & 880.8 & 5 & 54 & 44 & 898.8 & LO 601.3 & LL 599.4 & \\
& OOLn & $2.0 \pm 0.0$ & 880.8 & 5 & 54 & 44 & 898.8 & OLn 599.4 & OO 603.4 & \\
6 & SOLn & $0.3 \pm 0.0$ & 882.8 & 4 & 54 & 46 & 900.8 & SO 605.4 & SLn 601.4 & OLn 599.4 \\
\hline
\end{tabular}

Results are presented as mean value \pm standard deviation $(n=3)$.

P, palmitic acid; O, oleic acid; L, linoleic acid; Ln, linolenic acid; S, stearic acid; TAG, triacylglycerol; Mr, molecular mass; DB, double bond; $\mathrm{CN}$, carbon number; ECN, equivalent carbon number; $[\mathrm{M}+\mathrm{H}]^{+}$, pseudomolecolar ion; [DG $]^{+}$, diglyceryde ion.

Table 4 Relative abundance of TAG isomers in cold press Chinese perilla seed oil.

\begin{tabular}{cccc}
\hline Fraction & TAG & Isomers & $\begin{array}{c}\text { Relative abundance } \\
(\mathrm{mol} \% \text { of total })\end{array}$ \\
\hline \multirow{2}{*}{2} & \multirow{2}{*}{ LLnLn } & $s n$-LLnLn & $95.9 \pm 0.0$ \\
& & $s n$-LnLLn & $4.1 \pm 0.0$ \\
\hline \multirow{2}{*}{3} & \multirow{2}{*}{ PLnLn } & $s n$-PLnLn & $98.1 \pm 0.0$ \\
& & $s n$-LnPLn & $1.9 \pm 0.0$ \\
\hline \multirow{2}{*}{3} & \multirow{2}{*}{ LLLn } & $s n$-LLnL & $31.4 \pm 0.0$ \\
& & $s n$-LLLn & $68.6 \pm 0.0$ \\
\hline \multirow{2}{*}{4} & \multirow{2}{*}{ LnLP } & $s n$-LnLP & $93.9 \pm 0.0$ \\
& & $s n$-LnPL & $6.1 \pm 0.0$ \\
\hline \multirow{2}{*}{4} & \multirow{2}{*}{ LLnO } & $s n$-LLnO & $17.4 \pm 0.0$ \\
& & $s n$-LOLn & $67.2 \pm 0.0$ \\
\multirow{2}{*}{5} & \multirow{2}{*}{ PLnO } & $s n$-PLnO & $84.6 \pm 0.0$ \\
& \multirow{2}{*}{5} & $s n$-POLn & $15.4 \pm 0.0$ \\
\hline \multirow{2}{*}{6} & \multirow{2}{*}{ SOLO } & $s n$-LLO & $96.9 \pm 0.0$ \\
& & $s n$-OLOL & $3.1 \pm 0.0$ \\
\hline
\end{tabular}

Results are presented as mean value \pm standard deviation $(n=3)$.

P, palmitic acid; O, oleic acid; L, linoleic acid; Ln, linolenic acid; S, stearic acid; TAG, triacylglycerol.
Table 5 Composition of the hydrocarbons from cold press Chinese perilla seed oil.

\begin{tabular}{ccc}
\hline Retention time (min) & Compounds & $\begin{array}{c}\text { Content } \\
(\mathrm{mg} / \mathrm{kg} \text { oil })\end{array}$ \\
\hline 21.99 & Octadecane & $0.68 \pm 0.01$ \\
34.30 & Pentacosane & $5.07 \pm 0.07$ \\
37.27 & Heptacosane & $15.15 \pm 0.16$ \\
40.05 & Nonacosane & $23.12 \pm 0.21$ \\
Total hydrocarbons & & $44.02 \pm 0.45$ \\
\hline
\end{tabular}

Results are presented as mean value \pm standard deviation $(n=3)$.

LLnO (4.2 g/100 g), LnPL (2.5 g/100 g), OOLn(2.0 g/100 g), and so on. Relative abundance of TAG regioisomers was listed in Table 4. LLnO has three isomers, while other 7 TAGs all have two isomers. The total TAG profiles results showed that this oil contained 20 TAGs including 17 regioisomers.

\subsection{Unsaponifiable matters composition}

As shown in Tables 5-7, the unsaponifiable matters of Chinese perilla seed oil were composed of sterols, squalene, tocopherol, alcohols and hydrocarbons. Total hydrocarbons content was $44.02 \mathrm{mg} / \mathrm{kg}$.

As shown in Table 6, total alcohols content was 299.3 $\mathrm{mg} / \mathrm{kg}$, including phytol and farnesol with contents of 53.20 $\mathrm{mg} / \mathrm{kg}$ and $30.93 \mathrm{mg} / \mathrm{kg}$, respectively. Phytol and farnesol has good anti-carcinogenic, anti-inflammatory and antimetabolic-syndrome properties ${ }^{30,31)}$.

As shown in Table 7, the total phytosterols were mainly 
Table 6 Composition of the alcohols from cold press Chinese perilla seed oil.

\begin{tabular}{ccc}
\hline $\begin{array}{c}\text { Retention time } \\
(\mathrm{min})\end{array}$ & Compounds & Content (mg/kg oil) \\
\hline 11.91 & 1-Decanol & $1.12 \pm 0.01$ \\
12.03 & 1-Nonanol & $0.29 \pm 0.01$ \\
12.14 & Glycerol & $0.36 \pm 0.01$ \\
13.64 & 1-Decanol & $0.40 \pm 0.01$ \\
17.40 & 1-Dodecanol & $1.27 \pm 0.01$ \\
21.36 & 1-Tetradecanol & $0.84 \pm 0.01$ \\
29.18 & Phytol & $53.20 \pm 0.63$ \\
30.61 & Farnesol & $30.93 \pm 0.28$ \\
32.11 & 1-Eicosanol & $36.68 \pm 0.38$ \\
33.62 & 1-Heneicosanol & $1.80 \pm 0.01$ \\
35.16 & Docosanol & $37.44 \pm 0.42$ \\
36.58 & 1-Tricosanol & $6.50 \pm 0.05$ \\
38.06 & Tetracosanol & $52.96 \pm 0.44$ \\
39.36 & 1-Pentacosanol & $8.44 \pm 0.06$ \\
40.74 & 1-Hexacosanol & $67.08 \pm 0.88$ \\
Total alcohols & & $299.3 \pm 3.2$ \\
\hline
\end{tabular}

Results are presented as mean value \pm standard deviation $(n=3)$.

composed of campesterol, stigmasterol, $\beta$-sitosterol, isofucosterol and lanosterol. The total phytosterols content of the perilla seed oil $(0.39 \mathrm{~g} / 100 \mathrm{~g}$ oil $)$ was higher than that of the grape seed oil $\left(0.23-0.34 \mathrm{~g} / 100 \mathrm{~g}\right.$ oil ${ }^{20)}$ and the peanut oil $(0.28 \mathrm{~g} / 100 \mathrm{~g}$ oil $)$. Phytosterols have been reported to have important antioxidant, analgesic, anti-inflammatory and anticancer properties ${ }^{32,33)}$. The content of $\beta$-sitosterol was up to $0.31 \mathrm{~g} / 100 \mathrm{~g}$ oil. Other important sterols include campesterol $(273.3 \mathrm{mg} / \mathrm{kg})$, stigmasterol $(237.1 \mathrm{mg} / \mathrm{kg})$ and lanosterol $(201.7 \mathrm{mg} / \mathrm{kg})$. Campesterol and $\beta$-sitosterol have been proved to be effective in inhibiting intestinal cholesterol absorption in humans ${ }^{34,35)}$. The squalene content of the oil was tested to be $275.4 \mathrm{mg} / \mathrm{kg}$. It has been certified that squalene has several beneficial health effects, such as antioxidant activity, decreasing cancer, and reducing the side effects of chemotherapy ${ }^{36}$. $\delta$-Tocopherol and $\gamma$-tocopherol were also found with contents of $2.87 \mathrm{mg} / \mathrm{kg}$ and $151.5 \mathrm{mg} / \mathrm{kg}$, respectively. Previous studies reported the health benefits of tocopherols, including neuroprotective, cardioprotective and anti-inflammatory activities ${ }^{37)}$.

\section{Conclusions}

The results showed that the oil yield of the solvent extracted method was up to $39.61 \mathrm{~g} / 100 \mathrm{~g}$, higher than that of the cold press method (34.40 g/100 g). Both oil possessed low acid value and peroxide value. Total content of tocopherols in the solvent extracted oil was up to $743.3 \mathrm{mg} / \mathrm{kg}$ oil. The majority fatty acid of the Chinese perilla seed oil was linolenic acid $(66.4 \mathrm{~g} / 100 \mathrm{~g})$, followed by linoleic acid (15.3 $\mathrm{g} / 100 \mathrm{~g}$ ). The overall TAG profile showed that this oil contained 20 TAGs including 17 regioisomers, in which $\operatorname{LnLnLn}(35.8 \mathrm{~g} / 100 \mathrm{~g})$ was dominant. The unsaponifiable matters of this oil possessed high content of phytosterols ( $0.39 \mathrm{~g} / 100 \mathrm{~g}$ oil), among which $\beta$-sitosterol was the most predominant $(0.31 \mathrm{~g} / 100 \mathrm{~g}$ oil $)$. Therefore, the Chinese perilla seed oil is a good edible oil. And it also can be a good source of biological activity compounds, especially linolenic acid and $\beta$-sitosterol.

Table 7 Composition of the squalene, tocopherols and sterols from cold press Chinese perilla seed oil.

\begin{tabular}{ccc}
\hline Retention time $(\mathrm{min})$ & Compounds & Content $(\mathrm{mg} / \mathrm{kg}$ oil $)$ \\
\hline 39.29 & Squalene & $275.4 \pm 2.9$ \\
40.22 & delta-Tocopherol & $2.87 \pm 0.01$ \\
41.65 & gamma-Tocopherol & $151.5 \pm 1.3$ \\
Total tocopherols & & $154.4 \pm 1.3$ \\
44.94 & Campesterol & $273.3 \pm 2.1$ \\
45.26 & Stigmasterol & $237.1 \pm 2.4$ \\
45.40 & Ketocholesterol & $6.78 \pm 0.01$ \\
46.80 & beta-Sitosterol & $3110 \pm 27$ \\
46.05 & Isofucosterol & $85.8 \pm 0.7$ \\
47.93 & Lanosterol & $201.7 \pm 1.9$ \\
Total sterols & & $3914 \pm 33$ \\
\hline
\end{tabular}

Results are presented as mean value \pm standard deviation $(n=3)$. 


\section{Acknowledgments}

Financial support granted by Natural Science Foundation of Henan Province (202300410103) and Innovation Program of Henan University of Technology (2020ZKCJ20) are gratefully acknowledged.

\section{References}

1) Pan, F.; Wen, B.; Wang, X.; Ma, X.; Zhao, J.; Liu, C. et al. Effect of the chemical refining process on perilla seed oil composition and oxidative stability. J. Food Process. Pres. 43, e14094(2019).

2) Bondioli, P.; Folegatti, L.; Rovellini, P. Oils rich in alpha linolenic acid: Chemical composition of perilla (Perilla frutescens) seed oil. OCL 27, 67-71(2020).

3) Torri, L.; Bondioli, P.; Folegatti, L.; Rovellini, P.; Piochi, M.; Morini, G. Development of Perilla seed oil and extra virgin olive oil blends for nutritional, oxidative stability and consumer acceptance improvements. Food Chem. 286, 584-591 (2019).

4) Lee, K.Y.; Rahman, M.S.; Kim, A.N.; Jeong, E.J.; Kim, B.G.; Lee, M.H. et al. Oil yield, physicochemical characteristics, oxidative stability and microbial safety of perilla seeds stored at different relative humidity. Ind. Crop. Prod. 165, 113431 (2021).

5) Hashimoto, M.; Matsuzaki, K.; Hossain, S.; Ito, T.; Wakatsuki, H.; Tanabe, Y. et al. Perilla seed oil enhances cognitive function and mental health in healthy elderly Japanese individuals by enhancing the biological antioxidant potential. Foods 10, 1130 (2021).

6) Guo, H.; Chen, C.; Yan, X.; Li, Y.; Wen, X.; You, C. et al. Effects of different dietary oil sources on growth performance, antioxidant capacity and lipid deposition of juvenile golden pompano Trachinotus ovatus. Aquaculture 530, 735923(2021).

7) Zhang, H.X.; Tian, Y.H.; Guan, J.; Xie, Q.M.; Zhao, Y.Q. The anti-tussive, anti-inflammatory effects and subchronic toxicological evaluation of perilla seed oil. $J$. Sci. Food Agr. 101, 1419-1427 (2021).

8) Wei, M.C.; Wang, C.S.; Wei, D.H.; Yang, Y.C. Insights into the supercritical $\mathrm{CO}_{2}$ extraction of perilla oil and its theoretical solubility. Processes 9 (2), 13(2021).

9) Li, H.Z.; Zhang, Z.J.; Hou, T.Y.; Li. X.J.; Chen, T. Optimization of ultrasound-assisted hexane extraction of perilla oil using response surface methodology. Ind. Crop. Prod. 76, 18-24(2015).

10) Cui, K.; Ding, X.; Xiao, G.; Dai, J. Analysis of triacylglycerol composition of perilla oil by combination of non-aqueous reversed-phase high performance liquid chromatography with gas chromatography. Chin. J. Chromatogr. 15, 470-473(1997).

11) Rombaut, N.; Savoire, R.; Thomasset, B.; Castello, J.; Hecke, E.V.; Lanoisellé, J.L. Optimization of oil yield and oil total phenolic content during grape seed cold screw pressing. Ind. Crop. Prod. 63, 26-33 (2015).

12) Firestone, D. Official methods and recommended practices of the American Oil Chemists' Society: Official methods and recommended practices of the AOCS (1994).

13) Zhao, B.B.; Li, H.; Lan, T.; Wu, D.; Chen, Z.C. Characterization of the chemical composition of Chinese $\mathrm{Mo}^{-}$ ringa oleifera seed oil. J. Am. Oil Chem. Soc. 96, 523-533 (2019).

14) Lee, K.Y.; Rahman, M.S.; Kim, A.N.; Jeong, E.J.; Kim, B.G.; Lee, M.H. et al. Effect of superheated steam treatment on yield, physicochemical properties and volatile profiles of perilla seed oil. LWT-Food Sci. Technol. 135, 110240 (2021).

15) Zhao, B.B.; Gong, H.D.; Li, H.; Zhang, Y.; Deng, J.W.; Chen, Z.C. Fatty acid, triacylglycerol and unsaponifiable matters profiles and physicochemical properties of Chinese evening primrose oil. J. Oleo Sci. 68, 719$728(2019)$.

16) Wang, L.; Pang, M.; Wang, X.B.; Wang, P.; Xiao, Y.P.; Liu, Q.H. Characteristics, composition, and antioxidant activities in vitro and in vivo of Gynostemma pentaphyllum (Thunb.) Makino seed oil. J. Sci. Food Agr. 97, 2084-2093 (2017).

17) Li, H.Z.; Zhang, Z.J.; He, D.L.; Xia, Y.Y.; Liu, Q.Y.; Li, X.J. Ultrasound-assisted aqueous enzymatic extraction of oil from perilla seeds and determination of its physicochemical properties, fatty acid composition and antioxidant activity. Food Sci. Technol. 37, 71-77(2017).

18) Lee, K.Y.; Rahman, M.S.; Kim, A.N.; Son, Y.; Gu, S.; Lee, M.H. et al. Effect of freeze-thaw pretreatment on yield and quality of perilla seed oil. LWT-Food Sci. Technol. 122, 109026 (2021).

19) Zhu, M.; Wen, X.; Zhao, J.; Liu, F.; Ni, Y.; Ma, L. et al. Effect of industrial Chemical refining on the physicochemical properties and the bioactive minor components of peanut oil. J. Am. Oil Chem. Soc. 93, 285294(2016).

20) Wen, X.; Zhu, M.; Hu, R.; Zhao, J.; Chen, Z.; Li, J. et al. Characterisation of seed oils from different grape cultivars grown in China. J. Food Sci. Technol-Mysore. 53, 3129-3136 (2016).

21) Zaaboul, F.; Raza, H.; Chen, C.; Liu, Y.F. Characterization of peanut oil bodies integral proteins, lipids, and their associated phytochemicals. J. Food Sci. 83, 93100 (2018).

22) Liu, X.F.; Wang, S.; Masui, E.; Tamogami, S.; Chen, J.Y.; Zhang, H. Analysis of the dynamic decomposition of unsaturated fatty acids and tocopherols in commercial oils during deep frying. Anal Lett. 52, 1991-2005 (2019).

23) Konuskan, D.B.; Arslan, M.; Oksuz, A. Physicochemical properties of cold pressed sunflower, peanut, rape- 


\section{Perilla Seed Oil}

seed, mustard and olive oils grown in the Eastern Mediterranean region. Saudi J. Bio. Sci. 26, 340-344 (2019).

24) Sprague, M.; Xu, G.; Betancor, M.B.; Olsen, R.E.; Torrissen, O.; Glencross, B.D. et al. Endogenous production of n-3 long-chain PUFA from first feeding and the influence of dietary linoleic acid and the alphalinolenic:linoleic ratio in Atlantic salmon (Salmo salar). Brit. J. Nutr. 122, 1091-1102(2019).

25) Dubois, V.; Breton, S.; Linder, M.; Fanni, J.; Parmentier, M. Fatty acid profiles of 80 vegetable oils with regard to their nutritional potential. Eur. J. Lipid Sci. Tech. 109, 710-732 (2007).

26) Rodriguez, G.; Villanueva, E.; Cortez, D.; Sanchez, E.; Aguirre, E.; Hidalgo, A. Oxidative stability of chia ( $\mathrm{Sal}$ via hispanica L.) and sesame (Sesamum indicum L.) oil blends. J. Am. Oil Chem. Soc. 97, 729-735(2020).

27) Rincon-Cervera, M.A.; Valenzuela, R.; Hernandez-Rodas, M.C.; Barrera, C.; Espinosa, A.; Marambio, M. et $a l$. Vegetable oils rich in alpha linolenic acid increment hepatic n-3 LCPUFA, modulating the fatty acid metabolism and antioxidant response in rats. Prostag. Leukotr. Ess. 111, 25-35(2016).

28) Jang, S.I.; Fang, S.; Kim, K.P.; Ko, Y.; Kim, H.; Oh, J. et $a l$. Combination treatment with n-3 polyunsaturated fatty acids and ursodeoxycholic acid dissolves cholesterol gallstones in mice. Sci. Rep-UK. 9, 12740 (2019).

29) Hu, J.; Wei, F.; Dong, X.Y.; Lv, X.; Jiang, M.L.; Li, G.M. et $a l$. Characterization and quantification of triacylglycerols in peanut oil by off-line comprehensive twodimensional liquid chromatography coupled with atmospheric pressure chemical ionization mass spectrometry. J. Sep. Sci. 36, 288-300(2013).

30) Bobe, G.; Zhang, Z.; Kopp, R.; Garzotto, M.; Shannon, J.; Takata, Y. Phytol and its metabolites phytanic and pristanic acids for risk of cancer: Current evidence and future directions. Eur. J. Cancer Prev. 29, 191200(2019).
31) Souza, D.S.; Rodrigues, M.-F. J.E.; Santos-Miranda, A.; Guedes. de J. I.C.; Silva, N.J.A.; Guatimosim, S. et al. Calcium overload-induced arrhythmia is suppressed by farnesol in rat heart. Eur. J. Pharmacol. 859, 172488(2019).

32) Yang, Q.; Yu, D.; Zhang, Y. beta-Sitosterol attenuates the intracranial aneurysm growth by suppressing TNFalpha-mediated mechanism. Pharmacology 104, 303311 (2019).

33) Park, Y.J.; Bang, I.J.; Jeong, M.H.; Kim, H.R.; Lee, D.E.; Kwak, J.H. et al. Effects of beta-sitosterol from corn silk on TGF-beta1-induced epithelial-mesenchymal transition in lung alveolar epithelial cells. J. Agric. Food Chem. 67, 9789-9795(2019).

34) Tai, K.; Rappolt, M.; He, X.; Wei, Y.; Zhu, S.; Zhang, J. et al. Effect of beta-sitosterol on the curcumin-loaded liposomes: Vesicle characteristics, physicochemical stability, in vitro release and bioavailability. Food Chem. 293, 92-102(2019).

35) Driessche, J.J.; Plat, J.; Konings, M.C.J.M.; Mensink, R.P. Effects of spirulina and wakame consumption on intestinal cholesterol absorption and serum lipid concentrations in non-hypercholesterolemic adult men and women. Eur. J. Nutr. 59, 2229-2236(2019).

36) Pacetti, D.; Scortichini, S.; Boarelli, M.C.; Fiorini, D. Simple and rapid method to analyse squalene in olive oils and extra virgin olive oils. Food Control. 102, 240-244 (2019).

37) Trela, A.; Szymanska, R. Less widespread plant oils as a good source of vitamin E. Food Chem. 296, 160-166 (2019).

CC BY 4.0 (Attribution 4.0 International). This license allows users to share and adapt an article, even commercially, as long as appropriate credit is given. That is, this license lets others copy, distribute, remix, and build upon the Article, even commercially, provided the original source and Authors are credited. 